\title{
A study to assess the psychological impact of fetal loss among the postnatal mothers admitted in selected hospitals of district Faridkot, Punjab, India
}

\section{Anmol Bhatia*, Bhupinder Kaur, Nishi Garg}

Department of Obstetrics and gynaecology, G.G.S Medical College and hospital, faridkot, Punjab, India

Received: 15 March 2016

Accepted: 16 April 2016

\section{*Correspondence:}

Anmol Bhatia,

E-mail: anmolbhatia3@gmail.com

Copyright: () the author(s), publisher and licensee Medip Academy. This is an open-access article distributed under the terms of the Creative Commons Attribution Non-Commercial License, which permits unrestricted non-commercial use, distribution, and reproduction in any medium, provided the original work is properly cited.

\section{ABSTRACT}

Background: Miscarriage, spontaneous abortion of a fetus and the loss of an infant through stillbirth, or neonatal death is recognized as a traumatic life event before the expected point of viability. Women's response ranges from relief to devastation. Predictors of development of complicated grief after prenatal loss include lack of social support, pre-existing relationship difficulties, or absence of surviving children, as well as ambivalent attitudes or heightened perception of the reality of the pregnancy. The study aimed to assess the psychological impact of fetal loss among the postnatal mothers.

Methods: The research design selected for the study was non-experimental descriptive design. Study was conducted from Dec 2014 to Jan 2015 in obstetrics and gynaecology unit of G.G.S medical hospital, Faridkot, Punjab, India. 60 postnatal women were selected by convenience sampling. The perinatal grief scale (standardized tool) was used to assess fetal loss.

Results: The majority of women i.e. $76.7 \%$ had more psychological impact, $23.3 \%$ women had less psychological impact of fetal loss. The range of score varies from 62-129 with mean score 102.82 ,SD 15.21 ,standard error mean 1.963, and median 103.50 and a statistically significant relation was found between psychological impact of fetal loss and gravida, Number of fetal loss, Number of live births and period of gestation at $\mathrm{p}<0.05$.

Conclusion: Hence it can be concluded that majority of women had more psychological impact of fetal loss and association of psychological impact of fetal loss was found between number of previous loss, number of live births, gravida and period of gestation.

Key words: Fetal loss, Psychological impact, Postnatal mothers

\section{INTRODUCTION}

Psychological impact of fetal loss is defined as the entire process precipitated by loss through perinatal death. Perinatal death is defined as death of fetus during pregnancy at gestational age of 22 weeks and more or birth weight of $500 \mathrm{~g}$ and more or during the neonatal period. Support is defined as function that prevent or reduce stress in a women experiencing perinatal loss the support includes steps to make her feel accepted, respected, reassured that she was cared for and able to communicate freely and shared her experience and feelings. ${ }^{1}$
The loss of an infant through stillbirth, or neonatal death is recognized as a traumatic life event. Predictors of development of complicated grief after prenatal loss include lack of social support, pre-existing relationship difficulties, or absence of surviving children, as well as ambivalent attitudes or heightened perception of the reality of the pregnancy. Risk of complicated grief was found to be especially high after termination of a pregnancy due to fetal abnormality. ${ }^{2}$

The study was needed as childbirth has the potential of being one of the most joyous and fulfilling experience a woman goes through in her entire life, conversely the 
negative experiences with childbirth are rarely discussed. There is an overlooked category: mother who conceives but loses the baby in the womb. Not only are these women overlooked, but also the hospital care they receive proves inconsistent with the latest research. Nurse and doctors should be aware of latest research showing the most effective way to treat mother who have just experienced a stillbirth.

The immense responsibility of being present for the patient physically, emotionally, and spiritually should not be lost on the nurse. A woman is bringing both death and life into the world simultaneously. Whatever the cause of premature death, the pain remains long after the tragic loss. Although the loss of neonate is undoubtedly a delicate and uncomfortable situation, it is for these reasons this topic to be addressed. ${ }^{3}$

There is greatly increased vulnerability of women with perinatal death to experience negative psychological and social consequences. Stillbirth is a significant risk factor for depression and anxiety when they are assessed during a subsequent pregnancy.

There is an urgent need to develop appropriate mental health care services for mothers with perinatal deaths to develop positive family support and to prevent the postnatal mother from establishing depression resulting from fetal loss.

Main objectives of the study are: to assess the psychological impact of fetal loss among the postnatal mothers and to determine the association of psychological impact of fetal loss with selected demographic variables among postnatal mothers.

Fetal loss: is death of fetus irrespective of gestational age and weight of fetus. It includes miscarriage, intrauterine death and still birth.

Psychological impact: refers to emotional and interpersonal problems experienced by postnatal mothers after fetal loss.

Postnatal mothers: are mothers who had fetal loss i.e. miscarriage, intrauterine death and still birth.

\section{METHODS}

It was a quantitative research approach with nonexperimental descriptive design. And the study was conducted in G.G.S. Medical Hospital and Civil Hospital Faridkot, Punjab, India.

Various variables used in the study were age, educational status, occupation of mother, religion, area of residence, duration of marriage, gravida, number of antenatal checkups, number of ultrasound done, number of previous loss, number of live children, period of gestation, knowledge about fetal loss and type of family.
Assumption of study tells that mothers will experience negative psychological impact following fetal loss.

The target population of the study was postnatal women with fetal loss admitted in selected Hospitals of District Faridkot, Punjab.

Convenience sampling technique was used to select the sample. Total samples of 60 postnatal women with fetal loss admitted in selected hospitals of District Faridkot were selected for the study.

\section{Inclusion criteria}

Postnatal mothers:

- Who were admitted in selected hospitals of district Faridkot, Punjab.

- With recent fetal loss.

- Who were present at the time of data collection.

- Who were willing to participate.

\section{Exclusion criteria}

- Mothers who were not willing to participate in the study.

For the data collection an interview was schedule designed to collect patient's socio demographic profile of postnatal mothers. And PGS (PERINATAL GRIEF SCALE) are used. It was consisted of 33 items

\section{Criterion measure}

Total score: $33-165$

33-90-less psychological impact

91-165- more psychological impact

\section{RESULTS}

The analysis of data revealed that the range of psychological impact of fetal loss score was 62-129 with mean score 102.82 and standard deviation of 15.21 . Majority of the post natal mothers $31(51.7 \%)$ were in age group of 24-29 years. Majority of the post natal mothers were educated up to secondary $25(41.7 \%)$.

Most of post natal mothers 39(53.3\%) were housewives. Most of the post natal mothers $32(53.3 \%$ ) were from rural area. Distribution of the according to religion most of the postnatal mothers, $38(63.3 \%)$ were from Sikh religion.

As per the duration of marriage, maximum postnatal mothers $36(60.0 \%)$ were married from 1-5 years. As per distribution according to gravida, most of the postnatal mothers 38 (63.3\%) were multigravida. Maximum postnatal mothers $37(61.7 \%)$ had undergone 0-2 times antenatal check-ups. Majority of postnatal mothers 41 (68.3\%) had 0-2 times ultra sound during antenatal period. 
Table 1: Frequency and percentage distribution of study subjects according to selected socio demographic variables.

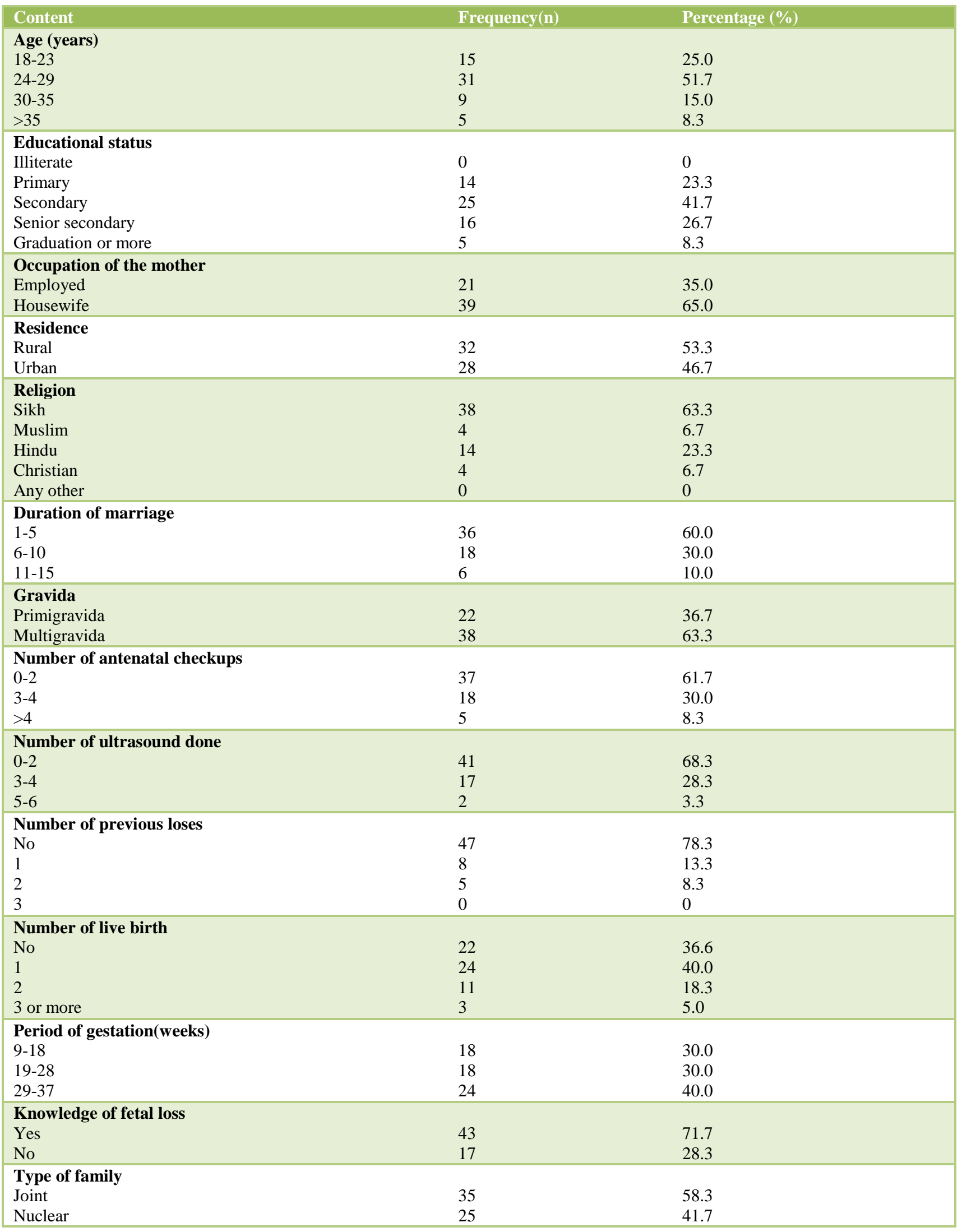


Most of the postnatal mothers 47(78.3\%) had no previous fetal loss. As per live births, maximum number of postnatal mothers $24(40.0 \%)$ had only 1 live birth. As per period of gestation, majority of postnatal mothers $24(40.0 \%)$ had period of gestation 29-37 weeks.

Table 2: Mean and Standard Deviation of psychological impact score of fetal loss among postnatal mothers, Total score 33-165.

\begin{tabular}{|ll|}
\hline Range & $62-129$ \\
\hline Mean & 102.82 \\
\hline \pm SD & 15.21 \\
\hline SEM & 1.963 \\
\hline Median & 103.50 \\
\hline
\end{tabular}

Table 3: Frequency and Percentage distribution of the postnatal mothers according to the psychological impact score of fetal loss.

\begin{tabular}{|lll|}
\hline Categories & $\begin{array}{l}\text { Number of } \\
\text { patients }\end{array}$ & Percentage \\
\hline $\begin{array}{l}\text { More psychological } \\
\text { impact }\end{array}$ & 46 & $76.70 \%$ \\
\hline $\begin{array}{l}\text { Less psychological } \\
\text { impact }\end{array}$ & 14 & $23.30 \%$ \\
\hline Total & 60 & $100 \%$ \\
\hline
\end{tabular}

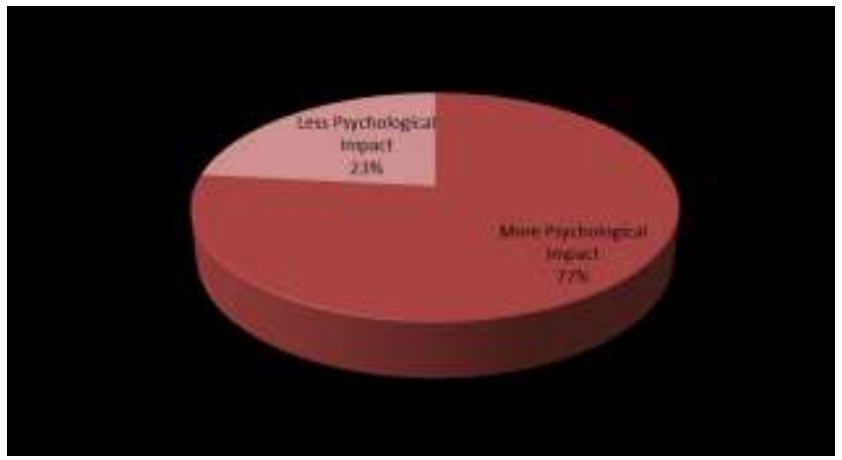

Figure 1: Frequency and percentage distribution of the postnatal women according to the psychological impact score of fetal loss.

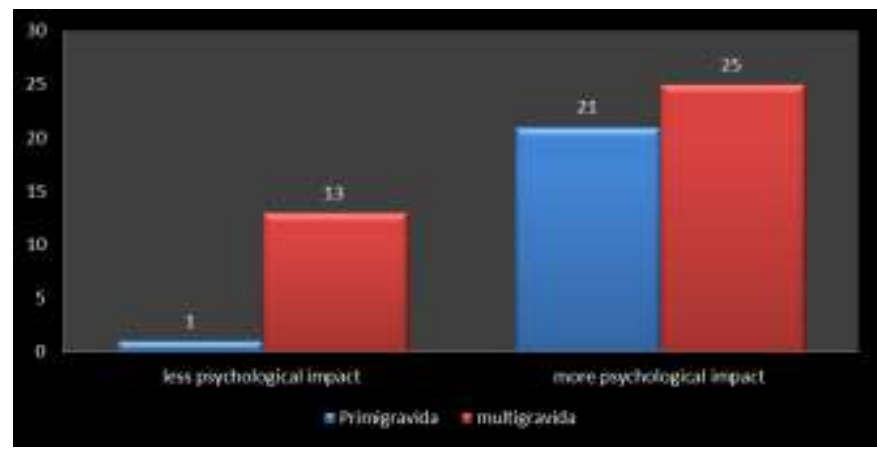

Figure 2: Association of psychological impact of fetal loss with gravida.

Table 4: Association of psychological impact of fetal loss with gravida.

\begin{tabular}{|c|c|c|c|c|c|}
\hline Gravida & $\begin{array}{l}\text { Less psychological } \\
\text { impact } \mathbf{n}(\%)\end{array}$ & $\begin{array}{l}\text { More psychological } \\
\text { impact } \mathbf{n}(\%)\end{array}$ & Total & $\begin{array}{l}\text { Chi square } \\
\text { value }\end{array}$ & p value \\
\hline Primigravida & $1(7.1 \%)$ & $21(45.7 \%)$ & 22 & \multirow{3}{*}{$\begin{array}{l}\chi^{2}=6.854 \\
\mathrm{df}=1\end{array}$} & \multirow{3}{*}{$0.009^{S}$} \\
\hline Multigravida & $13(92.9 \%)$ & $25(54.3 \%)$ & 38 & & \\
\hline Total & $14(100 \%)$ & $46(100 \%)$ & 60 & & \\
\hline
\end{tabular}

**Significant at $\mathrm{p}<0.05$

Table 5: Association of psychological impact of fetal loss with number of previous loses.

\begin{tabular}{|c|c|c|c|c|c|}
\hline $\begin{array}{l}\text { Number of } \\
\text { previous loss }\end{array}$ & $\begin{array}{l}\text { Less psychological impact } \\
\text { n }(\%)\end{array}$ & $\begin{array}{l}\text { More psychological impact } \\
\text { n }(\%)\end{array}$ & Total & $\begin{array}{l}\text { Chi square } \\
\text { value }\end{array}$ & p value \\
\hline 0 & $6(42.9 \%)$ & $40(87.0 \%)$ & 47 & \multirow{5}{*}{$\begin{array}{l}\chi^{2}=13.552 \\
\mathrm{df}=3\end{array}$} & \multirow{5}{*}{$0.001^{\mathrm{S}}$} \\
\hline 1 & $5(35.7 \%)$ & $3(6.5 \%)$ & 8 & & \\
\hline 2 & $3(21.4 \%)$ & $2(4.3 \%)$ & 5 & & \\
\hline 3 & 0 & 0 & 0 & & \\
\hline Total & $14(100 \%)$ & $46(100 \%)$ & 60 & & \\
\hline
\end{tabular}

** Significant at 0.05 level

Maximum number of postnatal mothers, 43 (71.7\%) had knowledge about the loss before delivery. Most of postnatal mothers, $35(58.3 \%)$ were from joint family.

Psychological impact of fetal loss among postnatal mothers had statistically significant association with age, educational status, occupation of the mother, residence, religion, duration of marriage, number of antenatal check-ups, number of ultrasounds done, knowledge about fetal loss and type of family.

Psychological impact of fetal loss among postnatal mothers had statistically significant association with gravida, number of previous loses number of live births and period of gestation. 


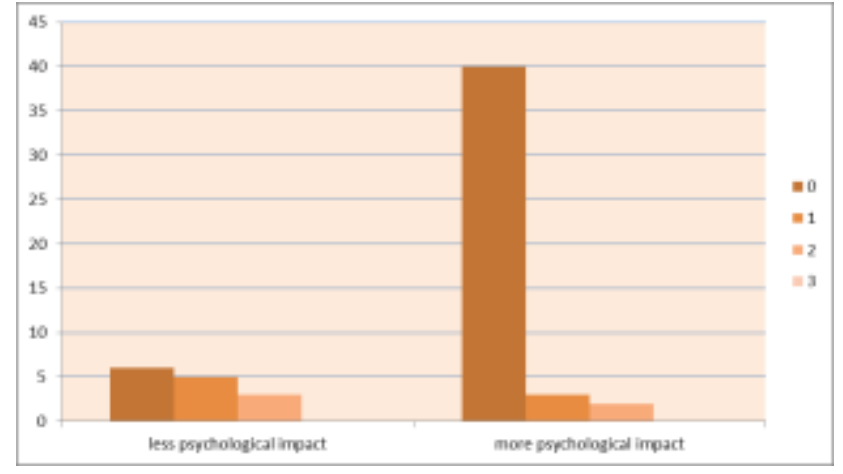

Figure 3: Association of psychological impact of fetal loss with number of previous loses.



Figure 4: Association of psychological impact of fetal loss with number of live births.

Table 6: Association of psychological impact of fetal loss with number of live birth.

\begin{tabular}{|c|c|c|c|c|c|}
\hline $\begin{array}{l}\text { Number of } \\
\text { live births }\end{array}$ & $\begin{array}{l}\text { Less psychological } \\
\text { impact } n(\%)\end{array}$ & $\begin{array}{l}\text { More psychological } \\
\text { impact } \mathbf{n}(\%)\end{array}$ & Total & $\begin{array}{l}\text { Chi square } \\
\text { value }\end{array}$ & p value \\
\hline 0 & $3(21.4 \%)$ & $31(67.4 \%)$ & 34 & \multirow{5}{*}{$\begin{array}{l}\chi^{2}=17.691 \\
\mathrm{df}=3\end{array}$} & \multirow{5}{*}{$0.001^{\mathrm{S}}$} \\
\hline 1 & $6(42.9 \%)$ & $12(26.1 \%)$ & 18 & & \\
\hline 2 & $5(35.7 \%)$ & $1(2.2 \%)$ & 6 & & \\
\hline 3 & 0 & $2(4.3 \%)$ & 2 & & \\
\hline Total & $14(100 \%)$ & $46(100 \%)$ & 60 & & \\
\hline
\end{tabular}

**Significant at 0.05 level

Table 7: Association of psychological impact of fetal loss with period of gestation (in weeks).

\begin{tabular}{|c|c|c|c|c|c|}
\hline $\begin{array}{l}\text { Period of } \\
\text { gestation }\end{array}$ & $\begin{array}{l}\text { Less psychological } \\
\text { impact } n(\%)\end{array}$ & $\begin{array}{l}\text { More psychological } \\
\text { impact } n(\%)\end{array}$ & Total & $\begin{array}{l}\text { Chi square } \\
\text { value }\end{array}$ & p value \\
\hline $9-18$ & $8(57.1 \%)$ & $10(21.7 \%)$ & 18 & \multirow{4}{*}{$\begin{array}{l}\chi 2=6.506 \\
d f=2\end{array}$} & \multirow{4}{*}{$0.039 \mathrm{~S}$} \\
\hline $19-27$ & $3(21.4 \%)$ & $15(32.6 \%)$ & 18 & & \\
\hline $29-37$ & $3(21.4 \%)$ & $21(45.7 \%)$ & 24 & & \\
\hline Total & $14(100 \%)$ & $46(100 \%)$ & 60 & & \\
\hline
\end{tabular}

** Significant at 0.05 level



Figure 5: Association of psychological impact of fetal loss with period of gestation (in weeks).

\section{DISCUSSION}

The present study findings revealed that the highest percentage $(76.6 \%)$ of the postnatal women belonged to more psychological impact category and $23.3 \%$ belonged to less psychological impact category. These findings were consistent with Lok IH suggested that miscarriage could be associated with significant and possibly enduring psychological consequences..$^{5}$ As many as $50 \%$ of miscarrying women suffered some form of psychological morbidity in the weeks and months after loss. About $40 \%$ of miscarrying women were found to be suffering from symptoms of grief shortly after miscarriage, and pathological grief can follow.

The present study with regards to the number of ultrasound done, the psychological impact of fetal loss among postnatal women found to be statistically nonsignificant ( $\mathrm{p}$ value 0.261 ) which was consistent with the findings of Salvesen KA who concluded that the long term psychological stress response in women to pregnancy termination following ultrasonographic detected (fetal anomalies) of fetal loss did not differ from the stress responses seen in women experiencing a perinatal loss. ${ }^{6}$

The present study showed statistically significant association of psychological impact of fetal loss with number of previous loss ( $\mathrm{p}$ value 0.01 ) and these findings were consistent with Carthy $\mathrm{McF}$ which revealed that 
previous pregnancy loss had an adverse impact on distress and behavior in women. ${ }^{7}$ Women with one previous miscarriage had increased anxiety, perceived stress, depression, and limiting/resting behavior in pregnancy than in women with two miscarriages. This study highlighted the psychological implications of miscarriage and termination of pregnancy.

The present study psychological impact of fetal loss found to be significant with period of gestational of women (in weeks) at $\mathrm{p}$ value 0.039 and these findings were consistent with Davies V which reveals that secondtrimester termination may be more stressful compared with first-trimester termination but these findings were inconsistent with Burgoine $\mathrm{G}$ A which revealed there was statistically non-significant difference in depression incidence on enrolment at 4 months, 12 months on the PGS. ${ }^{8,9}$ These findings were inconsistent with study conducted by Cowchock FS which concluded that the high levels of grief and PTS symptoms were significant problems for pregnant women who have suffered late loss of wanted pregnancy. ${ }^{10}$

\section{CONCLUSION}

Hence it can be concluded that majority of women had more psychological impact of fetal loss and association of psychological impact of fetal loss was found between number of previous loss, number of live births, gravida and period of gestation.

\section{ACKNOWLEDGEMENT}

It's a great privilege for Author to take this opportunity to express his sincere gratitude and profound reverence for my respected guide Mrs. Bhupinder Kaur, Professor, University College of Nursing, Faridkot. Without her remarkable vision and meticulous guidance in planning and evaluation of the work this effort of mine would have not yielded results. Author's thanks and humble regards to her for her wise expert opinion, encouragement and cooperation.

Author owes his inexplicable amount of indebtedness to my co-guide Dr. Nishi Garg (deparment of obstetrics and gynaecology GGSMH, Faridkot) for her cordial, considerate attitude and valuable suggestions. Without her unflinching support this thesis would have not been accomplished in its present form.

His sincere thanks goes to Prof H.C.L Rawat, Principal, University College of Nursing, Faridkot for his keen interest and clarifying queries at each step of this study. He earnestly wishes to thank my loving mother Mrs.Madhu Bala and my grandfather Mr. Jagdish lal
Bhatia for their constant encouragement, unending love and unconditional support and sacrifices. They are always a pillar of strength, a reason of my being where he is today. Above all, he would like to thank God Almighty for answering my prayers and for giving me the strength to accomplish this thesis.

\section{Funding: No funding sources}

Conflict of interest: None declared

Ethical approval: The study was approved by the Institutional Ethics Committee

\section{REFERENCES}

1. Swanson KM, R.N, F.A.A.N. Predicting depressive symptoms after miscarriage: a path analysis based on the lazarus paradigm. Journal of women's health and gender based medicine. 2000;9:30-6.

2. Psychological impact of fetal loss. [Internet]. Available from: URLhttp://www.ncbi.nlm.nih.gov/ pmc/ articles/ PMC2923205/ 2001;26(3):147-53.

3. Mills TA, Ricklesford C, Cooke A, Heazell AE, Whitworth M, Lavender T. Parents experiences and expectations of care in pregnancy after stillbirth or neonatal death: a metasynthesis.BJOG. 2014;121(8):943-50.

4. Dutta DC. Textbook of Obstetrics including Perinatology and Contraception. $6^{\text {th }}$ Ed. Calcutta: New Central Book Agency. 2004:368-74.

5. Lok IH. Psychological morbidity following miscarriage, Best Pract Res Clin Obstet Gynaecol. 2007;21(2):229-47.

6. Salvesen KA. Comparison of long-term psychological responses of women after pregnancy termination due to fetal anomalies and after perinatal loss. Ultrasound Obstet Gynecol. 1997;9(2):80-5.

7. Carthy MC, Moss Morris FP, Khalham Baker, Mc Lawan L. Previous pregnancy loss has an adverse impact on distress and behaviour in subsequent pregnancy. BJOG. 2015;10(11):1471-79.

8. Davies $\mathrm{V}_{-}$Psychological outcome in women undergoing termination of pregnancy for ultrasounddetected fetal anomaly in the first and second trimesters: a pilot study, Ultrasound Obstet Gynecol. 2005;25(4):389-92.

9. Burgoine GA. Comparison of perinatal grief after dilation and evacuation or labor induction in second trimester terminations for fetal anomalies. J Obstet Gynecol. 2005 jun;192(6):1928-32.

10. Cowchock FS. Religiosity is an important part of coping with grief in pregnancy after a traumatic second trimester loss. Relig Health. 2011;50(4):90110.

Cite this article as: Bhatia A, Kaur B, Garg N. A study to assess the psychological impact of fetal loss among the postnatal mothers admitted in selected hospitals of district Faridkot, Punjab, India. Int J Reprod Contracept Obstet Gynecol 2016;5:1607-12. 